\title{
Эфффект Пула-Френкеля в поликристаллическом сульфиде европия
}

\author{
(C) М.М. Казанин, В.В. Каминский , М.А. Гревцев \\ Физико-технический институт им. А.Ф. Иоффре Российской академии наук, \\ 194021 Санкт-Петербург, Россия \\ I E-mail: vladimir.kaminski@mail.ioffe.ru
}

Поступила в Редакцию 31 января 2019 г.

В окончательной редакции 4 февраля 2019 г.

Принята к публикации 14 февраля 2019 г.

Представлены результаты исследований полевых и температурных зависимостей электропроводности сульфида европия в интервале температур $160-430 \mathrm{~K}$. Выявлен рост электропроводности в сильных электрических полях до $2 \cdot 10^{4} \mathrm{~B} / \mathrm{cm}$ по механизму Пула-Френкеля.

Ключевые слова: сульфид европия, полупроводники, высокое напряжение, энергия активации.

DOI: 10.21883/FTP.2019.07.47862.9075

\section{1. Введение}

Одним из способов изменения параметров зонной структуры полупроводников может быть приложение к образцу высокого напряжения (эффект Пула-Френкеля $[1,2])$. Эффект заключается в том, что при приложении достаточно больших электрических полей к образцу полупроводника энергия активации электронов с электронных энергетических уровней уменьшается за счет добавления энергии поля. Сульфид европия $(\mathrm{EuS})$ применяется при изготовлении различных полупроводниковых приборов [3,4], при этом температурная область их функционирования зависит от энергии активации носителей заряда. Таким образом, представляет интерес изучение возможности изменения энергии активации электронов воздействием электрических полей, т. е. наличия и параметров эффекта Френкеля в EuS.

Теория эффекта изложена в $[1,2]$. Приложенное к полупроводниковому образцу электрическое поле напряженностью $F$ понижает энергию активации электронов проводимости, $E_{a}$, согласно следующему соотношению:

$$
E_{a}(F)=E_{a}(0)-\beta \sqrt{F},
$$

где $\beta$ - коэффициент Френкеля, связанный с диэлектрической проницаемостью материала, $\varepsilon$, и равный

$$
\beta=\sqrt{\frac{e^{3}}{\pi \varepsilon \varepsilon_{0}}} .
$$

При этом зависимость электропроводности полупроводника от поля и температуры выражается следующей формулой:

$$
\sigma=\sigma_{0} \exp \left(\frac{\beta \sqrt{F}}{k T}\right),
$$

где $\sigma_{0}$ - электропроводность образца в слабых полях.

\section{2. Методика эксперимента}

В данной работе для исследования полевых и температурных зависимостей электропроводности использо- вались поликристаллические образцы $\mathrm{EuS}$, полученные прямым синтезом из европия и серы с последующим прессованием и гомогенизирующим отжигом при $T=1600-1900^{\circ} \mathrm{C}$ [4]. По данным рентгеноструктурного анализа, образцы имели кубическую кристаллическую структуру типа $\mathrm{NaCl}$ с постоянной кристаллической решетки $a=5.96-5.97 \AA$. Образцы представляли собой сошлифованные до размеров $5 \times 2 \times 0.3$ мм пластинки EuS. Алюминиевые и серебряные планарные контакты с зазором 100 и 50 мкм наносились термическим распылением металлов в вакууме. Измерения полевых и температурных зависимостей электропроводности в температурном интервале $(160-430 \mathrm{~K})$ и электрических полях до $2 \cdot 10^{4} \mathrm{~B} / \mathrm{cm}$ проводились в вакуумном криостате при разрежении до $10^{-2}$ Па, снабженном резистивным нагревателем. Вольт-амперные характеристики при фиксированных температурах 77 и $293 \mathrm{~K}$ измерялись при прямом погружении образца в жидкий азот и при комнатной температуре. Электрическая измерительная схема снятия температурных зависимостей была традиционной и осуществлялась последовательным соединением источника ИСН-1, образца $\mathrm{EuS}$ и магазина калиброванных высокоомных сопротивлений. Величины падения напряжения на образце и образцовом сопротивлении регистрировались при помощи электрометрического комплекса ЭМ-1 с приставкой сопротивлений ПС-1, вольтметра Щ300 и вольтметра С-50.

\section{3. Обсуждение результатов}

На рис. 1 представлены температурные зависимости электропроводности $\mathrm{EuS}$ при различных величинах напряженности электрического поля в интервале температур $160-430 \mathrm{~K}$. Наблюдается соответствие полученных результатов формуле (1): уменьшение энергии активации проводимости при увеличении напряженности электрического поля, подаваемого на образец.

На рис. 2 представлены температурные зависимости энергии активации электронов, полученные дифференцированием температурной зависимости электропровод- 
ности по обратной температуре, $1000 / T$, при различных величинах напряженности электрического поля, подаваемого на образец. Наблюдается понижение энергии активации при повышении напряженности поля.

На рис. 3 представлены зависимости проводимости от величины напряженности электрического поля, полученные при $T=77 \mathrm{~K}$ (кривая 1 ) и $293 \mathrm{~K}$ (кривая 2 ). Наблюдается соответствие полученных результатов фор-

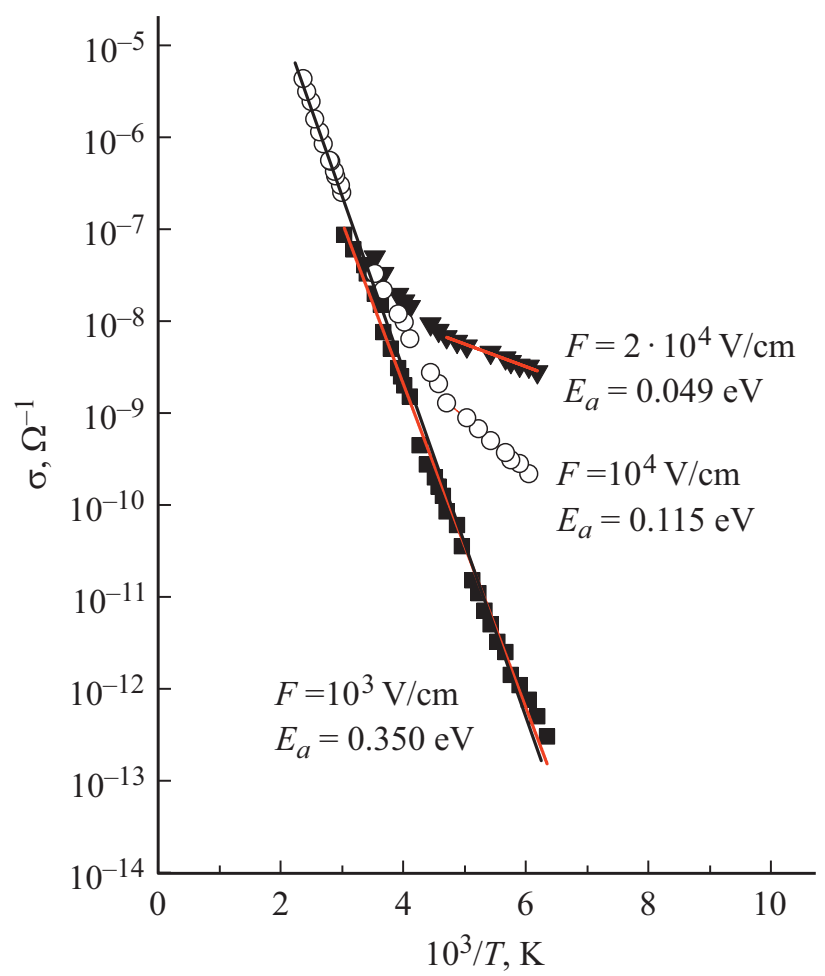

Рис. 1. Температурные зависимости электропроводности $\mathrm{EuS}$ при различных величинах напряженности электрического поля в интервале температур $160-430 \mathrm{~K}$.



Рис. 2. Температурная зависимость энергии активации проводимости в $\mathrm{EuS}$ при различных величинах напряженности электрического поля, подаваемого на образец.



Рис. 3. Зависимости проводимости от прикладываемой напряженности электрического поля, полученные при $T=77 \mathrm{~K}$ (кривая 1) и $293 \mathrm{~K}$ (кривая 2).

муле (3): логарифм проводимости линейно зависит от квадратного корня из величины напряженности электрического поля, а наклон этой зависимости увеличивается с понижением температуры, так как он пропорционален $\beta / k T$.

\section{4. Заключение}

Таким образом, из полученных данных следует, что эффект Пула-Френкеля в $\mathrm{EuS}$ наблюдается в наших экспериментах при температурах ниже комнатной. При температурах выше комнатной он отсутствует, по крайней мере, при величинах приложенного напряжения до $2 \cdot 10^{4} \mathrm{~B} / \mathrm{cm}$. Наличие эффекта Пула в $\mathrm{EuS}$ может позволить применять воздействие высоких напряжений на параметры различных приборов на основе этого полупроводника. Наиболее реальным представляется применение эффекта Пула в газовых сенсорах и преобразователях тепловой энергии в электрическую на основе термовольтаического эффекта.

\section{Финансирование работы}

Исследование выполнено при финансовой поддержке РФФИ в рамках научного проекта № 19-08-00576.

\section{Конфликт интересов}

Авторы заявляют, что у них нет конфликта интересов. 


\section{Список литературы}

[1] Я.И. Френкель. ЖЭТФ, 8 (12), 1292 (1938).

[2] А.М. Пашаев, Б.Г. Тагиев, О.Б. Тагиев. ФТТ, 55 (5), 861 (2013).

[3] С.А. Казаков, В.В. Каминский, С.М. Соловьев, Н.В. Шаренкова. Патент РФ на изобретение № 2623658. Приоритет от 22.03.2016.

[4] А.В. Голубков, Е.В. Гончарова, В.П. Жузе, Г.М. Логинов, В.М. Сергеева, И.А. Смирнов. Физические свойства халькогенидов редкоземельных элементов (Л., Наука, 1973).

Редактор Г.А. Оганесян

The Poole-Frenkel effect in polycrystalline europium sulphide

M.M. Kazanin, V.V. Kaminski, M.A. Grevtsev

loffe Institute,

194021 St. Petersburg, Russia

Abstract The paper presents the results of studies of the field and temperature dependences of the electrical conductivity of europium sulphide in the temperature range of $160-430 \mathrm{~K}$. An increase in electrical conductivity in strong slectric fields up to $2 \cdot 10^{4} \mathrm{~V} / \mathrm{cm}$ by the Poole-Frenkel mechanism has been revealed. 